\title{
Long-Term Arsenic Monitoring with an Enterobacter cloacae Microbial Fuel Cell \\ Michelle Rasmussen ${ }^{\mathrm{a}}$ and Shelley D. Minteer ${ }^{\mathrm{a}, *}$ \\ ${ }^{a}$ Department of Chemistry and Materials Science and Engineering, University of Utah, $315 \mathrm{~S}$ \\ 1400 E Room 2020, Salt Lake City, UT 84112 \\ *Corresponding Author: Phone: (801)587-8325, Email: minteer@chem.utah.edu
}

\begin{abstract}
A microbial fuel cell was constructed with biofilms of Enterobacter cloacae grown on the anode. Bioelectrocatalysis was observed when the biofilm was grown in media containing sucrose as the carbon source and methylene blue as the mediator. The presence of arsenic caused a decrease in bioelectrocatalytic current. Biofilm growth in the presence of arsenic resulted in lower power outputs whereas addition of arsenic showed no immediate result in power output due to the short term arsenic resistance of the bacteria and slow transport of arsenic across cellular membranes to metabolic enzymes. Calibration curves plotted from the maximum current and maximum power of power curves after growth show that this system is able to quantify both arsenate and arsenate with low detection limits ( $46 \mu \mathrm{M}$ for arsenate and $4.4 \mu \mathrm{M}$ for arsenite). This system could be implemented as a method for long-term monitoring of arsenic concentration in environments where arsenic contamination could occur and alter the metabolism of the organisms resulting in a decrease in power output of the self-powered sensor.
\end{abstract}

Keywords: bioelectrocatalysis, microbial fuel cells, arsenic detection, Enterbacter cloacae 


\section{Introduction}

Arsenic is a highly toxic element that is also a known carcinogen. It is naturally found in the environment; however, there has been a large increase in environmental arsenic concentrations due to its use in industrial applications such as pesticides. Toxic levels of arsenic have been detected in a number of countries, most specifically in Asia where several countries have reported arsenic levels higher than $10 \mu \mathrm{g} / \mathrm{L}$, the World Health Organization's maximum permissible limit. ${ }^{1}$ A large number of arsenic species are found in the environment, but two of the most common are arsenate (oxidation state +5 ) and arsenite (oxidation state +3 ). ${ }^{2}$

Arsenic has a high affinity for thiol groups and may bind to cysteine residues of proteins. It can also react with the dithiol lipoic acid which is a cofactor for two enzymes. The first is the pyruvate dehydrogenase complex where binding of the cofactor to arsenic leads to allosteric inhibition of the enzyme and prevents the formation of acetyl coenzyme A from pyruvate. Another enzyme affected in a similar way is $\alpha$-ketoglutarate dehydrogenase, a component of the citric acid cycle. With the inhibition of these two enzyme complexes, aerobic energy production from carbohydrates and lipids is prevented. ${ }^{3}$

Certain microorganisms, including E. coli, S. cerevisiae, and Enterobacter cloacae, have systems that make them resistant to arsenic. Due to the similar structure to phosphate, arsenate oxyanions are brought into the cell by phosphate membrane transport systems. It is reduced to arsenite by arsenate reductase and then arsenite efflux proteins pump it out of the cytoplasm. This prevents the intercellular arsenic concentration from becoming too high. ${ }^{4}$ Some microorganisms also have systems which can methylate the arsenic, forming organic arsenic compounds such as methylarsonic acid and trimethylarsine, which are less toxic than the inorganic compounds. ${ }^{5}$ The possible routes of arsenic metabolism are shown in Scheme 1.

[Insert Scheme 1 here]

There are a number of techniques currently used to detect and measure arsenic in water. One simple procedure involves extracting or digesting the sample to obtain arsenic ions in solution and then testing using one of several spectrophotometric methods, such as Inductively Coupled Plasma-Atomic Emission Spectrometry (ICP-AES) or Inductively Coupled PlasmaMass Spectrometry (ICP-MS), to determine the concentration. Other methods of analyzing samples containing arsenic include Gas Chromatography-Mass Spectrometry (GC-MS), Gas Chromatography-Tandem Mass Spectrometry (GC-MS/MS), Liquid Chromatography-Mass Spectrometry (LC-MS), Nuclear Magnetic Resonance Spectoscopy (NMR), and Ion Mobility Spectroscopy (IMS). ${ }^{1}$ These procedures require equipment that can be quite bulky and expensive as well as preparation of the sample which can be time-consuming. ${ }^{6}$ For testing in the field, portable X-ray fluorescence equipment has been developed. ${ }^{7}$ Colorimetric field kits are also available, but they are less sensitive. However, all of these methods involve collecting samples and evaluating the arsenic concentration. In environments where arsenic contamination is very likely, such as acidic mining conditions ${ }^{4}$, monitoring the arsenic overtime would be beneficial.

Self-powered sensors are a more recent class of sensors which consist essentially of a fuel cell in which the power output changes based on the concentration of the target analyte. Katz et 
al. reported the first self-powered enzymatic sensors in $2001 .^{8}$ This was the first use of the term self-powered sensor, but any MFC-based detection system reported prior to this would also fit into this category. They described the detection of glucose or lactate by biofuel cells over the concentration range 1-80 mM. Detection was possible by measuring the increase in power output with increasing fuel concentrations. Subsequently, the Minteer Research Group group reported a self-powered nitroaromatic explosives sensor utilizing mitochondria for detection ${ }^{9}$ as well as an enzymatic self-powered EDTA biosensor. ${ }^{10}$ Another common detection method for self-powered biosensors takes advantage of enzymatic inhibitor effects. In this method, the sensor operates at a constant fuel concentration and produces an open circuit voltage (OCV) and current and power outputs in the absence of the inhibitor. With increasing concentrations of inhibitor, the current and power outputs decrease due to inhibition of the enzymatic electrode (either anode or cathode depending on the inhibitor being detected). Similar methods have been used for the detection of herbicides, ${ }^{11} \mathrm{Hg}^{2+},{ }^{12}$ acetaldehyde, ${ }^{13}$ and cyanide. ${ }^{14}$

Instead of using either an enzyme or organelle as the biological catalyst for self-powered sensing, a microbial catalyst is an ideal choice due to their increased stability. Some MFCs have been shown to operate for years. ${ }^{15}$ The use of MFCs as a biosensor has been previously shown for target analytes such as lactate, ${ }^{16}$ biochemical oxygen demand, ${ }^{17}$ arabinose, ${ }^{18}$ and formaldehyde. $^{19}$ A genetically engineered Shewanella oneidensis MFC was used to detect arsenite over a concentration range of $0-100 \mu \mathrm{M}$ with a limit of detection of $40 \mu \mathrm{M} .^{20}$ They hypothesized that their MFC could also be used to detect arsenate but it was not evaluated for that purpose.

For a long-term sensor, an MFC is an ideal situation. For example, the sensor could be used to power a small light. When the concentration of the target analyte goes above a certain threshold the power would drop and the light would go out, warning that the concentration is too high. In this work, MFCs containing the bacteria Enterobacter cloacae at the anode were used for the detection of arsenic in solution. Biofilms were grown on the electrode in the absence and presence of arsenic compounds. The presence of arsenic during growth shows a significant decrease in power output from the MFC. Both arsenite and arsenate were detected with this system over a larger concentration range and lower detections limits than previously reported.

\section{Materials and methods}

\subsection{Chemicals and materials}

All chemicals were purchased from Sigma-Aldrich (St. Louis, MO) and used as received unless specified otherwise. Carbon felt (3.18 mm thick) was purchased from Alfa Aesar.

\subsection{Culture growth}

Enterobacter cloacae (ATCC 39978) was rehydrated in LB media (10 g/L tryptone, $5 \mathrm{~g} / \mathrm{L}$ yeast extract, and $10 \mathrm{~g} / \mathrm{L}$ sodium chloride). After incubation at $30^{\circ} \mathrm{C}$ for $24 \mathrm{~h}$, several $\mathrm{mL}$ were added to $100 \mathrm{~mL}$ of fresh $\mathrm{LB}$ media. The culture was incubated at $30^{\circ} \mathrm{C}$ for $24 \mathrm{~h}$ and aliquots were stored in $20 \%$ glycerol at $-80^{\circ} \mathrm{C}$. In preparation for use in the microbial fuel cell, LB media was inoculated with the glycerol stock and incubated at $30^{\circ} \mathrm{C}$ until the $\mathrm{OD}_{600}$ was $\sim 1.0$. This typically took $\sim 16$ hours. 


\subsection{Microbial fuel cell set-up}

The fuel cell consisted of anode and cathode compartments separated by a Nafion 212 membrane. The cathode compartment was filled with $0.1 \mathrm{M} \mathrm{pH} 7.4$ phosphate buffer and $20 \% \mathrm{Pt}$ on Vulcan XC-72 carbon cloth (E-tek, $2 \mathrm{~cm} \times 6 \mathrm{~cm}$ ) was used as the oxygen reduction cathode. A $50 \mathrm{~mL}$ aliquot of the E. cloacae culture was added to the anode compartment. A carbon felt anode $(1 \mathrm{~cm} \times 6 \mathrm{~cm})$ was used. The end of the anode was coated in wax to prevent wicking of the solution to the lead. In order to ensure reproducibility biofilm growth, $3 \mathrm{~cm}$ of the felt were not coated with wax and this entire surface was submerged into the culture. The fuel cell was connected and the open circuit voltage (OCV) was measured for $24 \mathrm{~h}$ to allow for biofilm growth. For reproducibility, it was crucial that the growth time and the exposed felt surface area were consistent.

\subsection{Electrochemical experiments}

All electrochemical experiments were performed with either a Bio-Logic VSP 4-channel electrochemical work station (for current ramp potentiometry) or a $\mathrm{CH}$ Instruments CHI611E (for cyclic voltammetry). After $24 \mathrm{~h}$ incubation, the MFC was evaluated electrochemically. Cyclic voltammetry was performed at a scan rate of $1 \mathrm{mV} / \mathrm{s}$ using the carbon felt anode in the same culture solution but the cathode is replaced with a $\mathrm{Ag} / \mathrm{AgCl}$ reference electrode $(0.197 \mathrm{~V}$ vs. SHE) and a Pt counter electrode. Current ramp potentiometry (CRP) was performed in the MFC configuration with a scan rate of $10 \mathrm{nA} / \mathrm{s}$. All experiments were performed in triplicate and the results show the average for the three trials.

\section{Results and Discussion}

[Insert Figure 1 here]

E. cloacae has previously been used in MFCs but with limited characterization. ${ }^{21-23}$ In order to optimize our system, the MFCs were initially tested by CV and CRP in the absence of arsenic. As shown in Figures 1A and 2A, when the biofilm was grown in only LB media (black line), there are no significant peaks observed in the $\mathrm{CV}$ other than oxygen reduction at negative potentials and only small power and current was shown in the power curve. Sucrose was chosen as a carbon source because it has been shown to enhance biofilm growth with E. cloacae. $^{24}$ Similar results were seen when sucrose was present in the growth medium (red line). This indicates that the biofilm is not capable of performing efficient direct electron transfer to the electrode.

[Insert Figure 2 here]

In order to do mediated electron transfer instead, methylene blue (MB) was chosen because it has been previously used in an E. cloacae MFC. ${ }^{23}$ When the biofilm was grown in the presence of $\mathrm{MB}$ (blue line), the expected redox peak at $-0.175 \mathrm{~V} v \mathrm{vs} . \mathrm{Ag} / \mathrm{AgCl}$ was observed in the $\mathrm{CV}$ and the current and power increase. However, when the biofilm was grown in medium containing both sucrose and MB (green line), bioelectrocatalytic oxidation was observed and the current and power observed in the power curve was significantly larger. The maximum current and power measured with this MFC, $14 \pm 1 \mu \mathrm{A}$ and $50 \pm 5 \mu \mathrm{W}$, respectively, are similar to previous E. cloacae MFCs which all reported currents or powers in the low $\mu \mathrm{As}$ or $\mu \mathrm{Ws} .^{21-23}$ 
Control experiments, shown in Figures $2 \mathrm{~B}$ and 3B, performed under the same conditions but with no bacteria show no bioelectrocatalytic current in the CV and the power curves show much smaller current and power output.

[Insert Figure 3 here]

For initial testing with arsenic, amperometric experiments were performed measuring the current at an applied voltage of $0 \mathrm{~V}$ to the MFC. After the current stabilized, injections of either arsenate or arsenite in solution were added. However, no change in current was observed over the time of the experiment $(1 \mathrm{~h}$ ) with concentrations of arsenic going up to $1 \mathrm{mM}$ (data not shown). This result is not surprising because the metabolism of the inorganic arsenic compounds and inhibitory effects of metabolism are not instantaneous, since there are a pool of metabolites already in the bacterial cell and transport across cellular membranes to metabolic enzymes is slow. As seen in Scheme 1, there are a number of pathways this can occur. In addition to the time need for the bacteria to respond to the arsenic, it also takes time for the mediator to move through the solution, to the bacteria, and back to the electrode for electron transfer. The response time of this system is not fast enough for this technique.

In order to allow the biofilm to have more time to respond to the arsenic, the biofilms were grown in the absence and presence of arsenic in media containing sucrose and MB. Figure 3 shows a comparison of $\mathrm{CVs}$ for the biofilms. When either $1 \mathrm{mM}$ arsenate (blue line) or $1 \mathrm{mM}$ arsenite (red line) are included in the growth medium, the bioelectrocatalytic oxidation current was not observed. This indicates that the arsenic compounds inhibit at least some of the microbial reactions which are mediated by the methylene blue.

[Insert Figure 4 here]

As shown in Figure 4, when grown in either $1 \mathrm{mM}$ arsenate or $1 \mathrm{mM}$ arsenite the current and power output decreased significantly. In $1 \mathrm{mM}$ arsenate the maximum current decreased $\sim 60 \%$ and the maximum power decreased $\sim 65 \%$ while in $1 \mathrm{mM}$ arsenite the decreases were $\sim 50 \%$ and $\sim 55 \%$, respectively. However, if the biofilm is grown normally and arsenic is added to the MFC after, no immediate decrease in current or power is observed (see Figure 5). When arsenate is added to the MFC (Figure 5A), no trend is observed with increasing concentration. With added arsenite (Figure 5B), the maximum current decreases slightly and the maximum power increases slightly, but no trend is observed with increasing concentration. Due to the slow current scan rate for these experiments, each MFC was evaluated for $>10$ hours and no significant current or power decrease was observed over that time. These results indicate that simply adding arsenic to the bacteria does not cause an immediate decrease in the current and power output. The arsenic must be present in solution during the biofilm growth which allows enough time for the bacteria to metabolize the arsenic, resulting in the decrease observed.

[Insert Figure 5 here]

To confirm that this system could be used to detect arsenic, MFCs were constructed and exposed to varying concentrations of either arsenate or arsenite. As seen in Figure 6, power curves for the MFCs show decreasing current and power with increasing concentrations of either arsenic species. Calibration curves were plotted using either the maximum current or maximum 
power from the power curves (Figure 7). For arsenite, both calibration curves show a linear response over the concentration that was tested $(0-0.5 \mathrm{mM})$. Above that concentration range, the power curves did not change significantly (data not shown). Linear fits to the calibration curves for arsenite give sensitivities of $0.044 \pm 0.003 \mu \mathrm{A} / \mathrm{mM}$ and $0.0117 \pm 0.0004 \mu \mathrm{W} / \mathrm{mM}$. The arsenite detection limits are $46 \mu \mathrm{M}$ when measuring the current and $4.4 \mu \mathrm{M}$ when measuring the power. A similar trend can be observed with arsenate present in the MFC. Over the same concentration range, the sensitivities are $0.030 \pm 0.004 \mu \mathrm{A} / \mathrm{mM}$ and $0.0042 \pm 0.0009 \mu \mathrm{W} / \mathrm{mM}$ with slightly higher detection limits $(46 \mu \mathrm{M}$ measuring current and $177 \mu \mathrm{M}$ measuring power). It is also important to note that for some reason the polarization curves for $0.15 \mathrm{mM}$ arsenate show a different shape than all the other results as seen in Figure 6B. It is unclear why this occurred but all three trials at that concentration showed a similar shape so these results were not included in the calibration curves. The results from these experiments show that this MFC shows a marked improvement over the previously reported one. ${ }^{20}$ The linear concentration range is 5 times larger with a limit of detection for arsenite that is an order of magnitude smaller. This MFC is also able to detect arsenate which has not previously been done with a self-powered MFC system.

\section{[Insert Figure 6 here]}

\section{Conclusions}

In this work, a system for long-term monitoring of arsenic concentration in water was developed. The system consists of a microbial fuel cell with biofilms of Enterobactero cloacae on the anode. The MFC showed bioelectrocatalytic oxidation when the biofilm was grown in sucrose and methylene blue. The presence of inorganic arsenic, either arsenate or arsenite, during biofilm growth leads to a decrease in power output from the MFC. This decrease was not observed during short analysis after the addition of arsenic, since arsenic response times at bacterial electrodes are greater than 1 hour and less than 24 hours. A linear decrease in both current and power was observed with increasing concentration, giving a detection limit of $46 \mu \mathrm{M}$ for arsenate and $4.4 \mu \mathrm{M}$ for arsenite, an order of magnitude lower than a previously reported MFC. The linear response was observed over a larger concentration range $(0-0.5 \mathrm{mM})$ than the previous system as well. These results indicate that this system could function as an arsenic indicator. This would be especially useful in environments where arsenic contamination commonly occurs, such as acidic mining, but the contamination occurs over time periods of days to weeks. A decrease in power output would serve as a warning that the arsenic concentration has increased and the appropriate response could be made. Further experiments are required in order to study the selectivity for arsenic. In environmental samples there will likely be other components that could inhibit the bacteria in a similar manner. One way to control for this would be to set up two MFCs in tandem: one with the E. cloacae biofilm and one with a biofilm of an arsenic-resistant bacteria. If arsenic is present, only the E. cloacae MFC will show a larger decrease in power output compared to the control MFC.

\section{Acknowledgements}


Generous funding for this project was provided by the United States Department of Agriculture (Grant \#1132204). 


\section{References}

1. D. Q. Hung, O. Nekrassova and R. G. Compton, "Analytical methods for inorganic arsenic in water: a review." Talanta, 2004, 64, 269-277.

2. H. M. Anawar, "Arsenic speciation in environmental samples by hydride generation and electrothermal atomic absorption spectrometry." Talanta, 2012, 88, 30-42.

3. D. Noort, H. P. Benschop and R. M. Black, "Biomonitoring of Exposure to Chemical Warfare Agents: A Review." Toxicology and Applied Pharmacology, 2002, 184, $116-$ 126.

4. R. Mukhopadhyay, B. P. Rosen, L. T. Phung and S. Silver, "Microbial arsenic: from geocycles to genes and enzymes." FEMS Microbiol. Rev., 2002, 26, 311-325.

5. S. Silver, L. T. Phung and B. P. Rosen, "Arsenic metabolism: resistance, reduction, and oxidation." Environmental chemistry of arsenic, 2001, 247-272.

6. K. Wrobel, K. Wrobel and J. A. Caruso, "Pretreatment procedures for characterization of arsenic and selenium species in complex samples utilizing coupled techniques with mass spectrometric detection." Anal. Bioanal. Chem., 2005, 381, 317-331.

7. D. Melamed, "Monitoring arsenic in the environment: a review of science and technologies with the potential for field measurements." Anal. Chim. Acta, 2005, 532, 113.

8. $\quad$ E. Katz, A. F. Bueckmann and I. Willner, "Self-powered enzyme-based biosensors." J. Am. Chem. Soc., 2001, 123, 10752-10753.

9. M. Germain, R. L. Arechederra and S. D. Minteer, "Nitroaromatic Actuation of Mitochondrial Bioelectrocatalysis for Self-Powered Explosive Sensors." J. Am. Chem. Soc., 2008, 130, 15272-15273.

10. M. Meredith and S. D. Minteer, "Inhibition and Activation of Glucose Oxidase bioanodes for Use in a Self-Powered EDTA Sensor." Anal. Chem., 2011, 93, 5436-5441.

11. M. Rasmussen and S. D. Minteer, "Self-Powered Herbicide Biosensor Utilizing Thylakoid Membranes." Analytical Methods, 2013, 5, 1140-1144.

12. D. Wen, L. Deng, S. Guo and S. Dong, "Self-Powered Sensor for Trace Hg2+ Detection." Anal. Chem. (Washington, DC, U. S.), 2011, 83, 3968-3972.

13. L. Zhang, M. Zhou and S. Dong, "A Self-Powered Acetaldehyde Sensor Based on Biofuel Cell." Anal. Chem., 2012.

14. L. Deng, C. Chen, M. Zhou, S. Guo, E. Wang and S. Dong, "Integrated Self-Powered Microchip Biosensor for Endogenous Biological Cyanide." Anal. Chem., 2010, 82, 42834287.

15. G. C. Gil, I. S. Chang, B. H. Kim, M. Kim, J. K. Jang, H. S. Park and H. J. Kim, "Operational parameters affecting the performance of a mediator-less microbial fuel cell." Biosens. Bioelectron., 2003, 18, 327-334.

16. H. Joo, M. S. Hyun, I. S. Chang and B. H. Kim, "A microbial fuel cell type lactate biosensor using a metal-reducing bacterium, Shewanella putrefaciens." J. Microbiol. Biotechnol., 1999, 9, 365-367.

17. B. H. Kim, I. S. Chang, G. C. Gil, H. S. Park and H. J. Kim, "Novel BOD (biological oxygen demand) sensor using mediator-less microbial fuel cell." Biotechnol. Lett, 2003, 25, 541-545.

18. F. Golitsch, C. Bücking and J. Gescher, "Proof of principle for an engineered microbial biosensor based on Shewanella oneidensis outer membrane protein complexes." Biosens. Bioelectron., 2013, 47, 285-291. 
19. X. Wang, N. Gao and Q. Zhou, "Concentration responses of toxicity sensor with Shewanella oneidensis MR-1 growing in bioelectrochemical systems." Biosens. Bioelectron., 2013, 43, 264-267.

20. D. P. Webster, M. A. TerAvest, D. F. Doud, A. Chakravorty, E. C. Holmes, C. M. Radens, S. Sureka, J. A. Gralnick and L. T. Angenent, "An arsenic-specific biosensor with genetically engineered Shewanella oneidensis in a bioelectrochemical system." Biosens. Bioelectron., 2014, 62, 320-324.

21. F. Rezaei, D. Xing, R. Wagner, J. M. Regan, T. L. Richard and B. E. Logan, "Simultaneous cellulose degradation and electricity production by Enterobacter cloacae in a microbial fuel cell." Appl. Environ. Microbiol., 2009, 75, 3673-3678.

22. S. Nambiar, C. Togo and J. Limson, "Application of multi-walled carbon nanotubes to enhance anodic performance of an Enterobacter cloacae-based fuel cell." African Journal of Biotechnology, 2009, 8.

23. Y. Mohan, S. Manoj Muthu Kumar and D. Das, "Electricity generation using microbial fuel cells." Int. J. Hydrogen Energy, 2008, 33, 423-426.

24. L. Thompson, V. Gray, D. Lindsay and A. Von Holy, "Carbon: nitrogen: phosphorus ratios influence biofilm formation by Enterobacter cloacae and Citrobacter freundii." $J$. Appl. Microbiol., 2006, 101, 1105-1113. 
Scheme 1 - one column figure

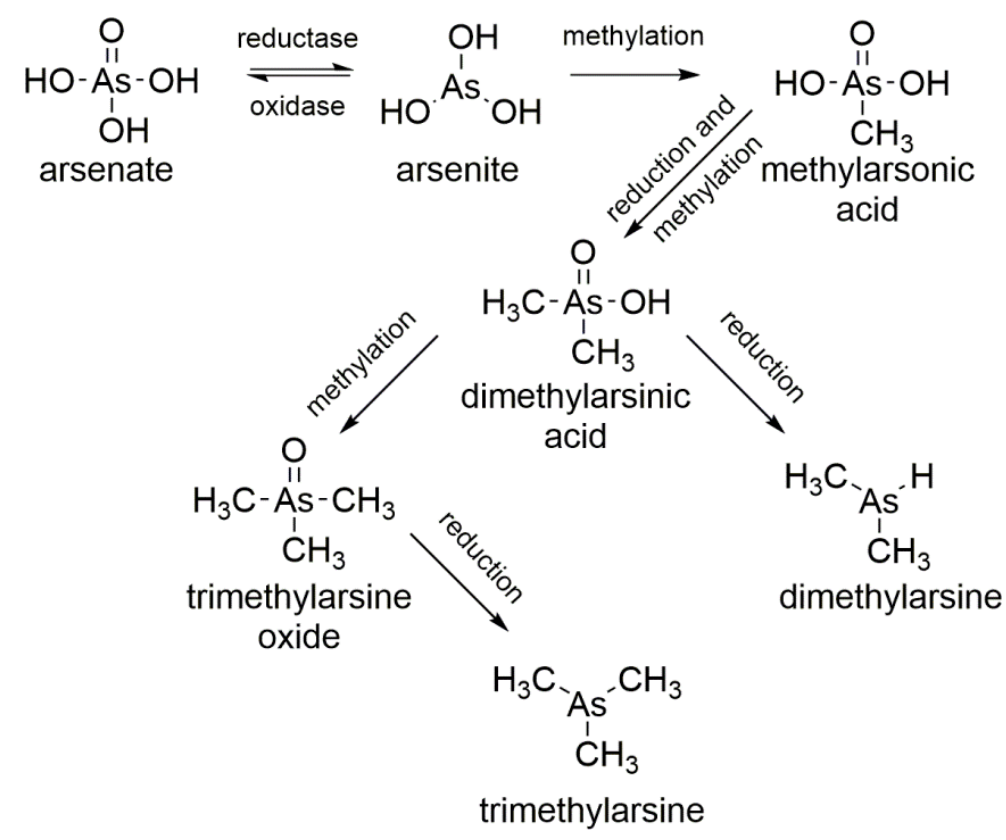


Figure 1 - two column figure
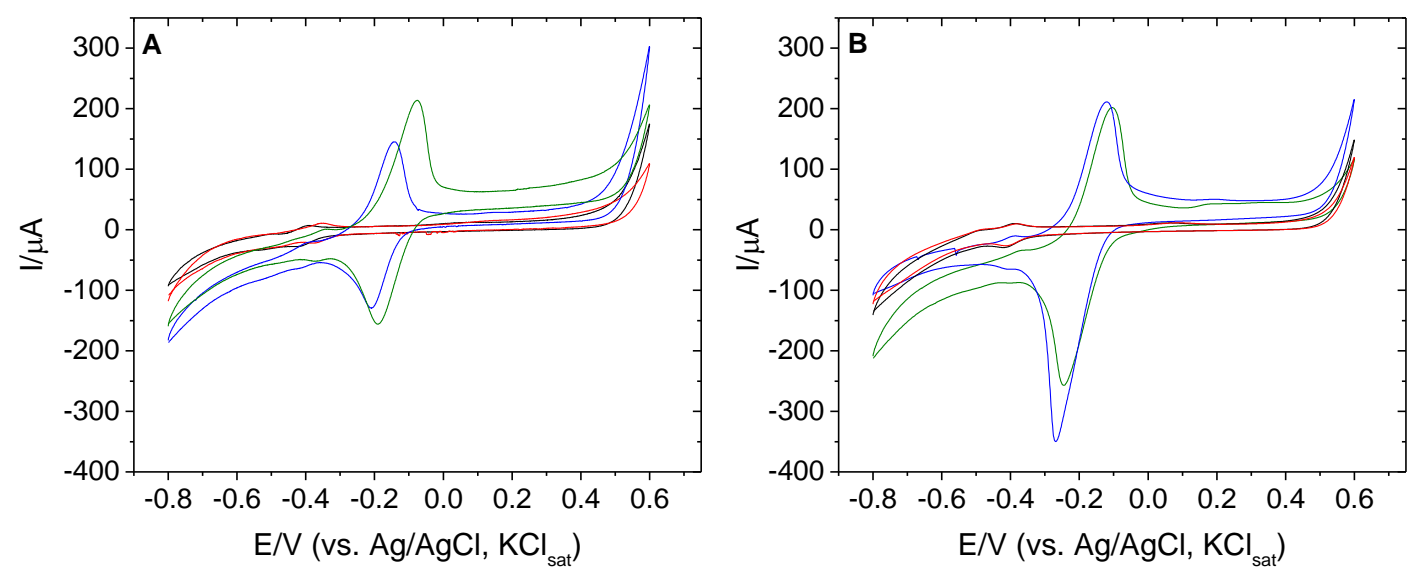
Figure 2 - two column figure
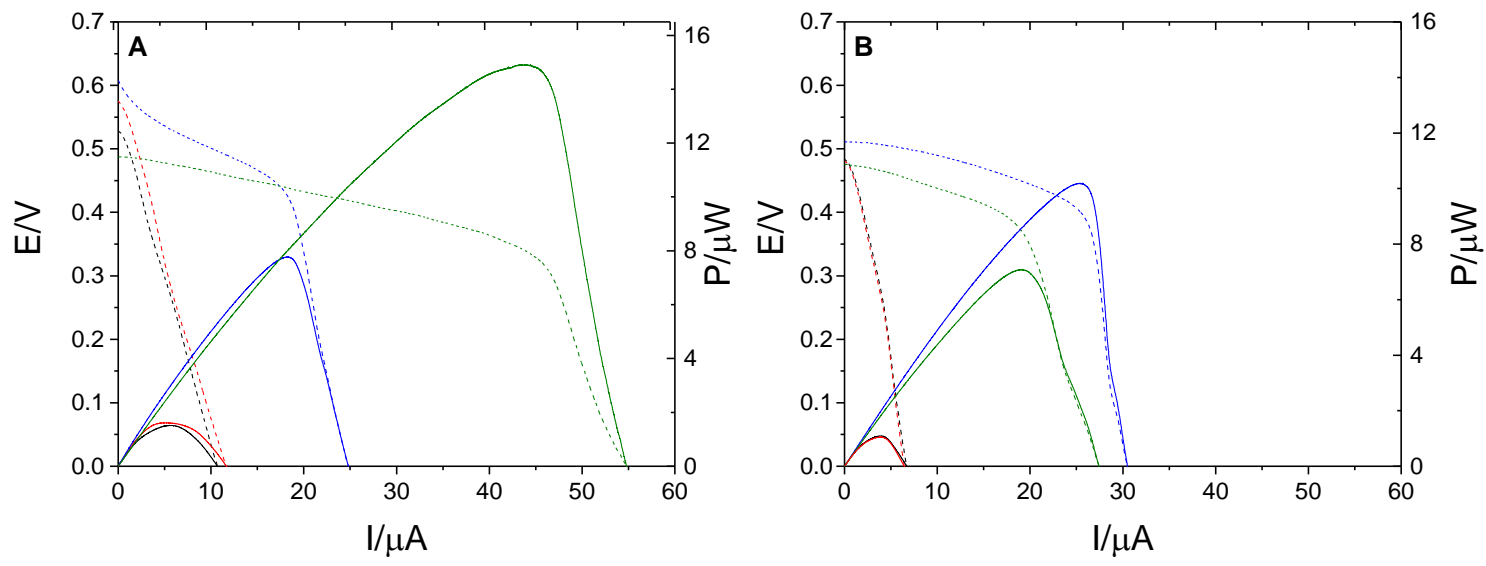
Figure 3 - single column figure

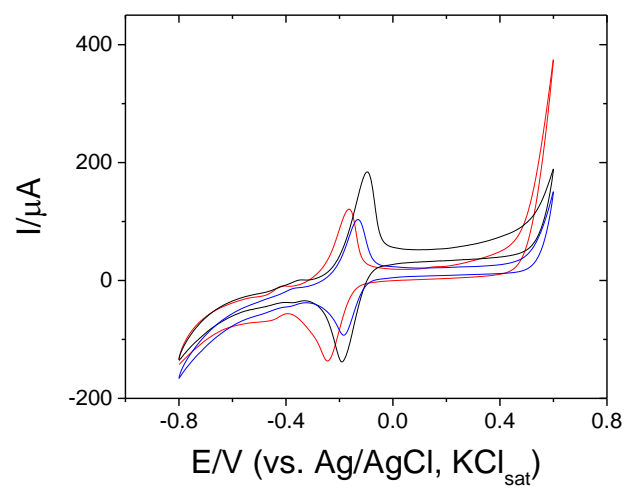


Figure 4 - single column figure

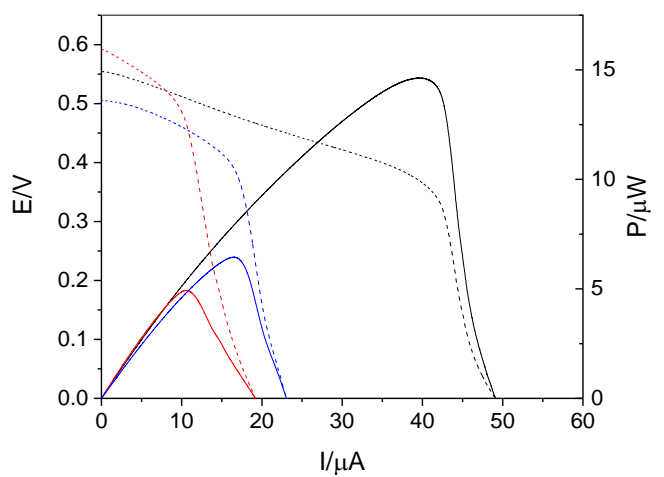


Figure 5 - two column figure
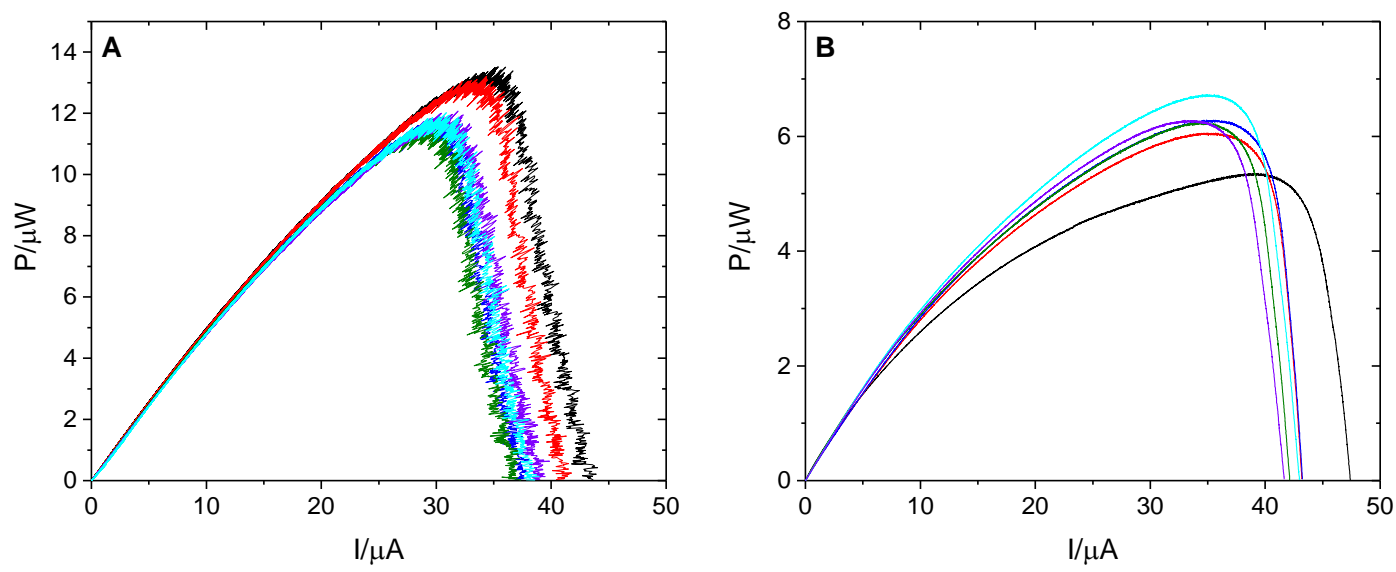
Figure 6 - two column figure
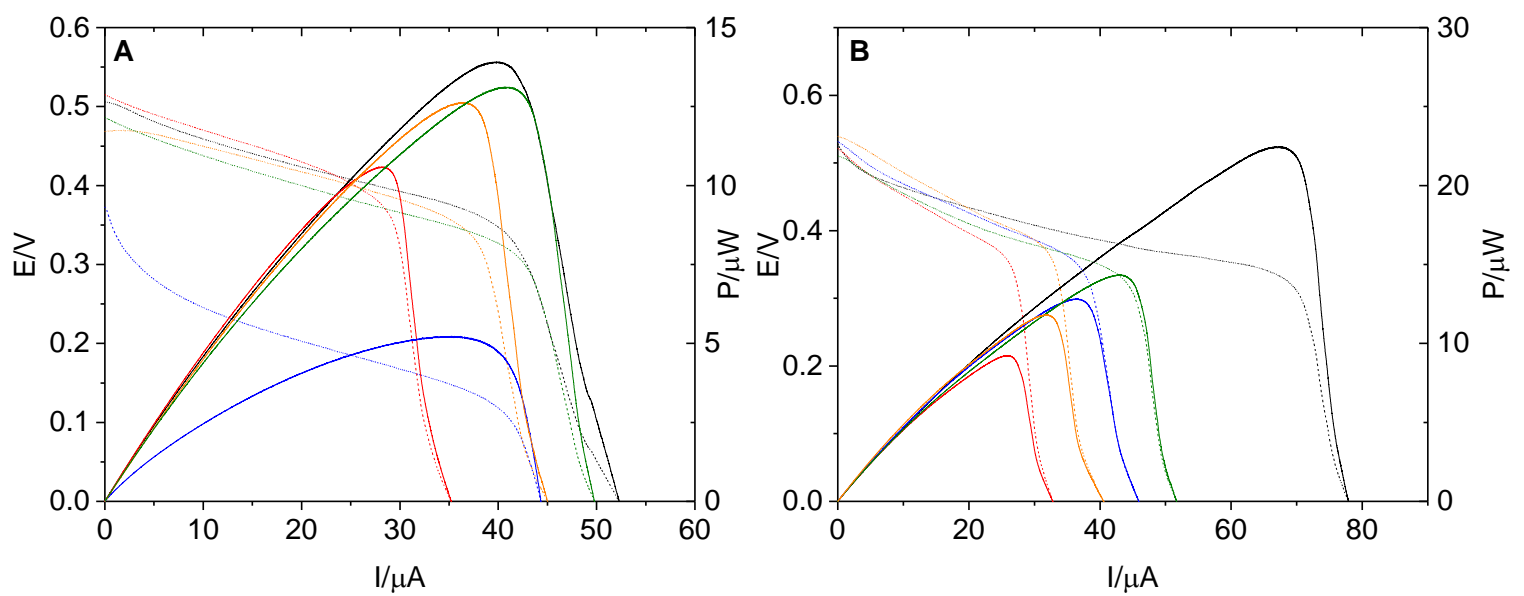
Figure 7 - two column figure
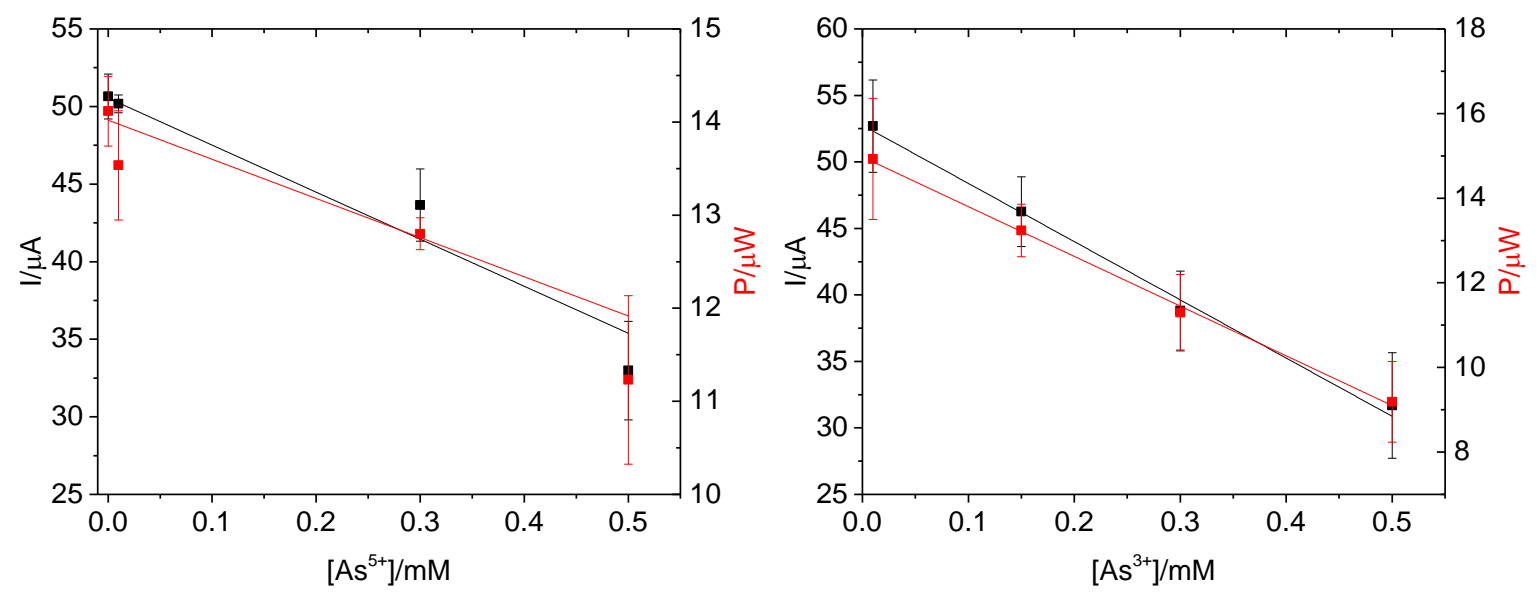


\section{Figure Captions}

Scheme 1. Mechanisms for microbial arsenic resistance. ${ }^{4}$

Fig. 1. Cyclic voltammograms recorded at $1 \mathrm{mV} / \mathrm{s}$ of carbon felt anode with (A) and without (B) biofilm grown in LB media (black), $4 \mathrm{~g} / \mathrm{L}$ sucrose (red), $0.3 \mathrm{mM} \mathrm{MB}$ (blue), and $4 \mathrm{~g} / \mathrm{L}$ sucrose and $0.3 \mathrm{mM} \mathrm{MB}$ (green).

Fig. 2. Current ramp potentiometry (dashed lines) and power curves (solid lines) recorded at 10 $\mathrm{nA} / \mathrm{s}$ for MFCs with (A) and without (B) biofilm grown in LB media (black), $4 \mathrm{~g} / \mathrm{L}$ sucrose (red), $0.3 \mathrm{mM} \mathrm{MB}$ (blue), and $4 \mathrm{~g} / \mathrm{L}$ sucrose and $0.3 \mathrm{mM} \mathrm{MB}$ (green).

Fig. 3. Cyclic voltammograms recorded at $1 \mathrm{mV} / \mathrm{s}$ of carbon felt anode with biofilm grown in LB media containing $4 \mathrm{~g} / \mathrm{L}$ sucrose and $0.3 \mathrm{mM} \mathrm{MB}$ (black) and $1 \mathrm{mM}$ arsenate (red) or $1 \mathrm{mM}$ arsenite (blue).

Fig. 4. Current ramp potentiometry (dashed lines) and power curves (solid lines) recorded at 10 $\mathrm{nA} / \mathrm{s}$ for MFCs with biofilm grown in LB media containing $4 \mathrm{~g} / \mathrm{L}$ sucrose and $0.3 \mathrm{mM} \mathrm{MB}$ (black lines) and $1 \mathrm{mM}$ arsenate (red lines) or $1 \mathrm{mM}$ arsenite (blue lines).

Fig. 5. Power curves recorded at $10 \mathrm{nA} / \mathrm{s}$ for MFCs with biofilm grown in LB media containing $4 \mathrm{~g} / \mathrm{L}$ sucrose and $0.3 \mathrm{mM} \mathrm{MB}$ (black lines) and arsenate (A) or arsenite (B) added to the anode compartment after growth. $0 \mathrm{mM}$ - black, $0.01 \mathrm{mM}$ - red, $0.05 \mathrm{mM}$ - blue, $0.15 \mathrm{mM}$ - green, 0.5 $\mathrm{mM}$ - purple, $1 \mathrm{mM}$ - cyan.

Fig. 6. Representative power curves recorded at $10 \mathrm{nA} / \mathrm{s}$ for MFCs with biofilm grown in LB media containing $4 \mathrm{~g} / \mathrm{L}$ sucrose, $0.3 \mathrm{mM} \mathrm{MB}$, and varying concentrations of arsenate (A) or arsenite (B). The arsenic concentrations are $0 \mathrm{mM}$ (black), $0.01 \mathrm{mM}$ (green), $0.15 \mathrm{mM}$ (blue), 0.3 $\mathrm{mM}$ (orange), and $0.5 \mathrm{mM}$ (red).

Fig. 7. Calibration curves constructed from plotting the maximum current (black) or maximum power (red) of MFCs with biofilm grown in LB media containing $4 \mathrm{~g} / \mathrm{L}$ sucrose and $0.3 \mathrm{mM} \mathrm{MB}$ and either arsenate $(\mathrm{A})$ or arsenite $(\mathrm{B})$. 


\section{Vitae}

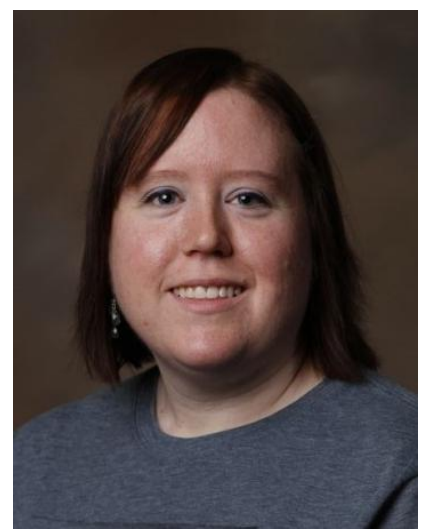

Michelle Rasmussen received her Ph.D. from Case Western Reserve University in 2012. She then joined the Minteer research group at the University of Utah as a postdoctoral researcher. She has worked on numerous projects including developing a bio-solar cell which incorporates thylakoid membranes for photosynthetic solar energy conversion. She is also studying how the plasmonic properties of nanoparticles affect their bioelectrocatalytic abilities.

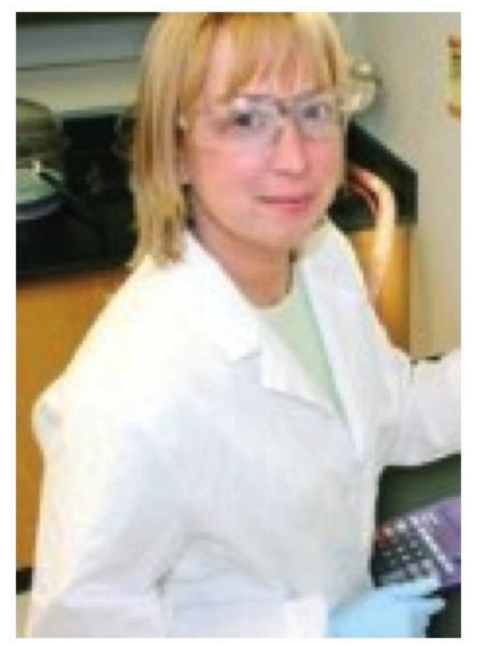

Shelley Minteer received her Bachelor of Science degree at Western Illinois University followed by a $\mathrm{PhD}$ in Analytical Chemistry at University of Iowa. She was a professor of chemistry at Saint Louis University from 2000 to 2011, before taking her current position as a USTAR Professor of Chemistry and Materials Science \& Engineering at University of Utah. Her research interests are in enzyme cascades and metabolons for deep oxidation of biofuels, biofuel cells, bioelectrocatalysis, and biosensors. 